\title{
Zero Ischemia Partial Nephrectomy of Renal Tumor
}

\author{
Anwar Alesawi* \\ Department of Urology, Doctor SulimanFakeeh Hospital (DSFH), Saudi Arabia
}

Submission: October 07, 2017; Published: November 29, 2017

*Corresponding author: Anwar Alesawi, Department of Urology, Doctor SulimanFakeeh Hospital (DSFH), Jeddah, Saudi Arabia, Tel: +966505683509; Email: esawi_anwar@yahoo.com

\begin{abstract}
Objective: Warm ischemic injury is one of the most important factors affecting renal function in Partial Nephrectomy (PN). The purpose of this study was to describe our initial case experience with preoperative tumor embolization of a renal tumor before performing partial nephrectomy.

Methodology: A 55 year old female patient with a solid hypervascular renal tumor with a RENAL nephrometry score of 7/15, was treated with a combination of preoperative tumor embolization and partial nephrectomy including a renal parenchymal clamping. Ethanol (100\%) was used to preoperativelyembolizes all major vessels supplying the tumor. The partial nephrectomy procedure was performed without clamping the renal vessels. This is the first case published up to date indicating this special technique that combines both preoperative embolization and intraoperative renal parenchymal clamping.

Results: Renal artery embolization and nephrectomy was successfully performed in our patient. There was no perioperative Morbidity or mortality. Hospital length of stay was 4 days. There was no evidence of tumor recurrence in the first 3 months. Preoperative radiological tumor size was $6 \mathrm{~cm}$ compared to $5 \mathrm{~cm}$ postoperatively in the gross histopathological report of the resected mass. Estimated blood loss was minimal $(<10 \mathrm{ml})$. Operative time was 120 minutes (including retrograde stent insertion). Histopathology demonstrated a pT1 renal cell carcinoma, with a negative tumor margin. Neither residual tumor nor recurrent tumor was identified by imaging studies in our case after a follow-up period of 8 months.
\end{abstract}

Conclusion: Our initial case experience suggests that combining both preoperative super selective tumor supplying artery embolization and applying a renal parenchymal clamp might reduce blood loss during partial nephrectomy, furthermore, might neither necessitate renal hilum manipulation nor vascular clamping. This is the first published case up to date that indicates and explains this technique. A larger sample with a longer follow-upwill be necessary to confirm efficacy.

Keywords: Angioembolization; Embolization; Partial nephrectomy

Abbreviations: PN: Partial Nephrectomy; TAE: Trans Arterial Embolization; STE: Superselective Transarterialtumor Embolization

\section{Introduction}
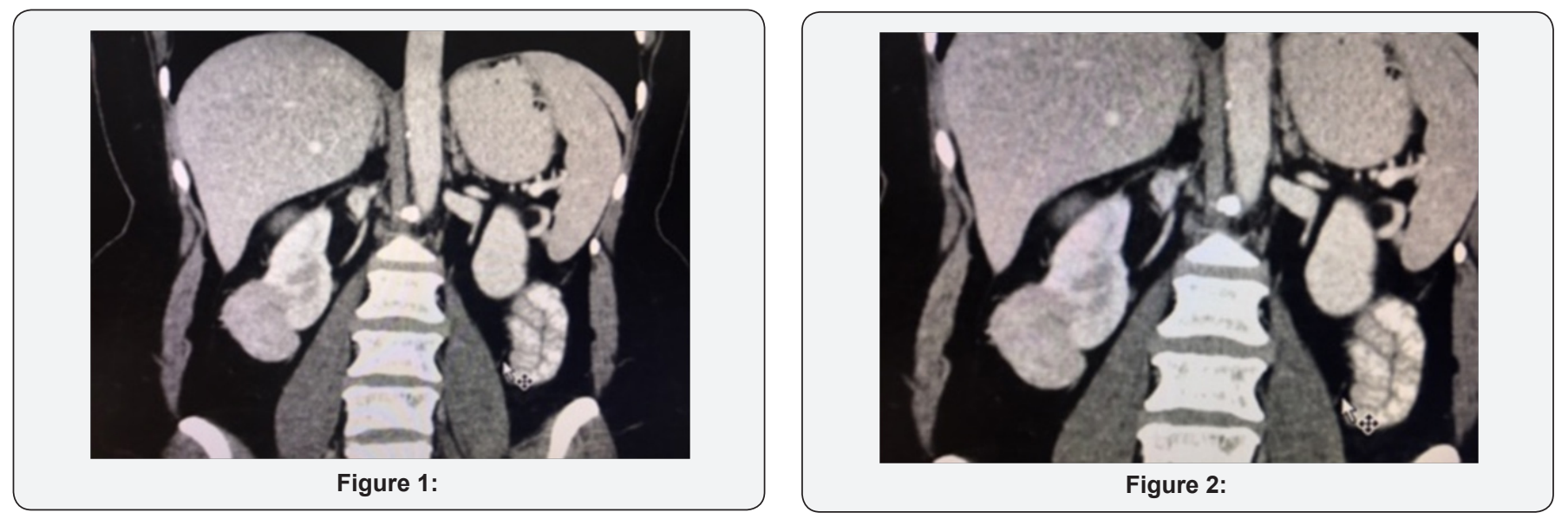
Warm ischemic injury is one of the most important factors affecting renal function in Partial Nephrectomy (PN). Renal hilar control is crucial to decrease intraoperative hemorrhage and to repair the renal collecting system. However, renal hilar control causes warm ischemia, with its attendant potential for ischemic renal injury [1] (Figure $1 \& 2$ ). The conventional method of renal hilar control is to clamp the renal artery alone or both the renal artery and vein. Therefore, renal vascular segmentation suggests that clamping branches of the renal artery can provide a bloodless operative field and a minimized risk of ischemic injury to most of the kidney. Trans Arterial embolization (TAE) of renal tumors was first described in 1973 as a preoperative aid to the resection of localized renal tumors and a means to palliate the symptoms of metastatic disease [2]. Kalman and Varenhorst reviewed published series and demonstrated that preoperative embolization could be used to reduce the size and vascularity of renal tumors, thus providing a mechanical advantage for any subsequent nephrectomy [3]. Ching-Chia Li et al. [4], described their initial experience with the application of TAE before laparoscopic partial nephrectomy, which was performed without clamping of renal vessels [4]. Here, we describe our initial experience with preoperative selective arterial embolization in combination with intraoperative renal parenchymal clamping without clamping renal vessels.

\section{Methodology}

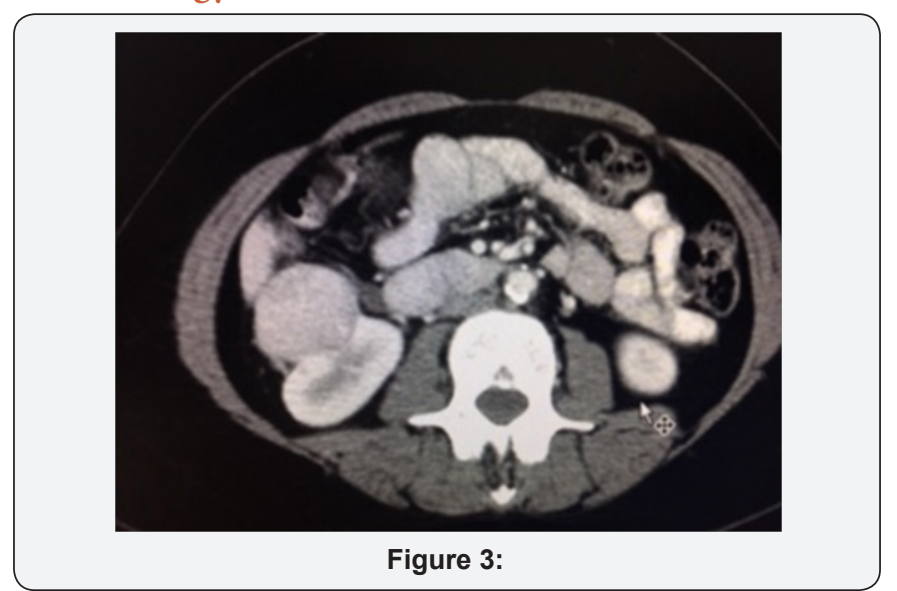

A 55 year old female patient with a solid hypervascular renal tumor that has a R.E.N.A.L. Nephrometry score of $7 / 15$, was treated with a combination of preoperative tumor embolization and partial nephrectomy including a renal parenchymal clamping. Ethanol (100\%) was used to preoperatively embolizes all major vessels supplying the tumor. The partial nephrectomy procedure was performed without clamping the renal vessels. This is the first case published up to date indicating this special technique that combines both preoperative embolization and intraoperative renal parenchymal clamping (Figure 3).

\section{Results}

Renal artery embolization and nephrectomy was successfully performed in our patient. There was no perioperative morbidity nor mortality. Hospital length of stay was 4 days. Preoperative radiological tumor size was $6 \mathrm{~cm}$ compared to $5 \mathrm{~cm}$ in postoperative gross histopathological report of tumor size. Estimated blood loss was minimal $(>10 \mathrm{ml})$. Operative time was 120 minutes (including retrograde stent insertion). Histopathology demonstrated a pT1 renal cell carcinoma, with a negative tumor margin. Neither residual tumor nor recurrent tumor was identified by imaging studies in our case after a follow-up period of 8 months (Figure $4 \& 5$ ).
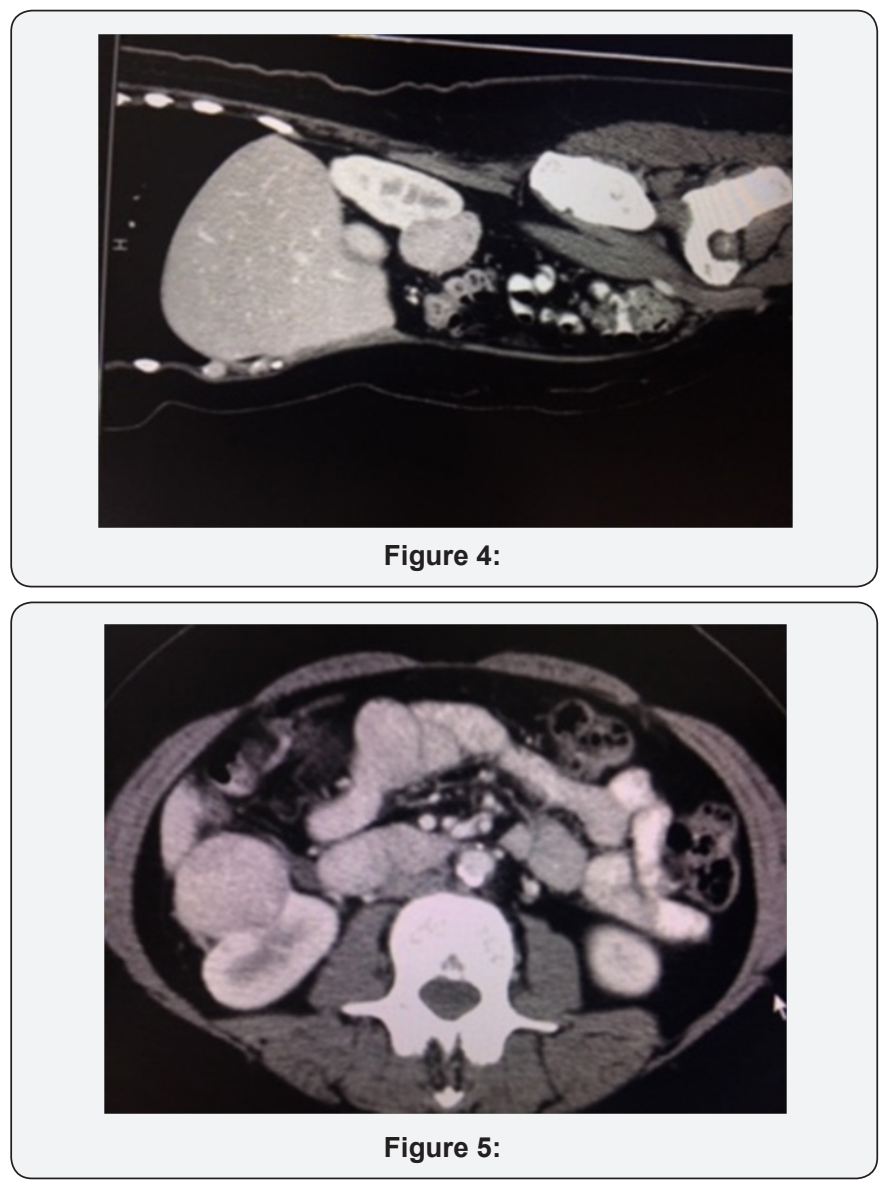

\section{Discussion}

The advantages of renal vascular clamping during PN are better visibility of the cutting surface [5], less blood loss and shorter operative time. On the other hand, there are benefits to performing PN without vascular clamping. First, it can avoid warm ischemic time and its associated risk of acute tubular necrosis. Second, it is not necessary to isolate renal vessels in every case, especially in patients whose renal pedicle is too hard to explore because of previous inflammation. Third, the complication rate of renal vessel injury is reduced.

Renal artery embolization is traditionally performed by an interventional radiologist. In this percutaneous procedure, the patient undergoes selective catheterization of the renal artery via the groin, followed by catheter-directed placement of embolic materials, such as alcohol or coils, to induce renal tumor 
infarction. A major concern with the staged approach is postinfarction syndrome, characterized by flank pain lasting 24 to 48 hours, nausea, vomiting, ileus, fever and leukocytosis associated with negative urine and blood cultures [6]. The syndrome is caused by acute infarction of a large parenchymal organ. Selective segmental artery embolization of renal tumor before partial nephrectomy has several advantages, like decreasing operative time as it does not include renal hilarmanipulation, smaller incision, In addition to the reduction in perioperative blood loss, risk of blood transfusion, hospitalization time and pain score. Although preoperative embolization can reduce blood loss, we must keep in mind the potential complications of angiography and embolization. In our described case, blood loss was almost nothing and skin incision was flank and small compared to our regular partial nephrectomy incision that include vascular clamping. Superselective TAE was done the day before PN and post infarction syndrome was well managed in hospital by pain killers. Our partial nephrectomy was simple as it did not include hilar manipulation nor clamping of renal vessels, in addition we applied a renal parenchymal clamp just proximal to the renal mass, that made our dissection in a real blood-less field.

Maksimov et al. [7] used intraoperative superselective balloon embolization of segmental branches of renal artery for intraoperative hemostasis during PN for renal malignancy that included renal vascular manipulation [7].

Giuseppe et al. [8] reported their 7 year experience with zero ischemia laparoscopic PN after Superselective Transarterialtumor Embolization (STE) and concluded that STE allowed them to perform a zero ischemia LPN and provided excellent functional results, adequate oncological results with low complications rate.STE significantly simplifies LPN [8].

D'Urso et al. [9] reported the feasibility, safety and effectiveness of zero ischemia LPN following preoperative STE, however, they mentioned that hilar clamping was necessary to achieve a relatively blood-less field in $17.4 \%$ of 23 cases [9].

\section{Conclusion}

Our initial case experience suggests that combining both preoperative super selective tumor supplying artery embolization and applying a renal parenchymal clamp might reduce blood loss during partial nephrectomy, furthermore, might neither necessitate renal hilum manipulation nor vascular clamping. This is the first published case up to date that indicates and explains this technique. A larger sample with a longer follow-up will be necessary to confirm efficacy.

\section{References}

1. Desai MM, Gill IS, Ramani AP, Spaliviero M, Rybicki L, et al. (2005) The impact of warm ischemia on renal function after laparoscopic partial nephrectomy. BJU Int 95(3): 377-383.

2. Almgard LE, Fernstrom I, Haverling M, Ljungqvist A (1973) Treatment of renal adenocarcinoma by embolic occlusion of the renal circulation. Br J Urol 45(5): 474-479.

3. Kalman D, Varenhorst E (1999) The role of arterial embolization in renal cell carcinoma. Scand J UrolNephrol 33(3): 162-170.

4. Li CC, Chou YH, Wu WJ (2007) Laparoscopic Partial Nephrectomy: The Effect Of Preoperative Tumor Embolization. Kaohsiung J Med Sci 23(12).

5. Guillonneau B, Bermudez H, Gholami S, El Fettouh H, Gupta R, et al. (2003) Laparoscopic partial nephrectomy for renal tumor: single center experience comparing clamping and no clamping techniques of the renal vasculature. J Urol 169(2): 483-486.

6. Weckermann D, Schlotmann R, Tietze W, Hackel T (1992) Gas formation after renal artery embolisation: genesis and clinical relevance. UrolInt 49(4): 211-214.

7. Maksimov AV, Martov AG, Pavlov LP, Neustroev PA, Vinokurov RR (2017) Laparoscopic partial nephrectomy with superselective balloon embolization of renal artery. Urologiia (1): 31-36.

8. Giuseppe S, Rocco P, Salvatore G, Livio C, Michele G (2011) Zero ischemia laparoscopic partial nephrectomy after superselectivetransarterial tumor embolization for tumors with moderate nephrometry score: long-term results of a single-center experience. J Endourol 25(9): 1443-1446.

9. D'Urso L, Simone G, Rosso R, Collura D, Castelli E, et al. (2014) Benefits and shortcomings of superselective transarterial embolization of renal tumors before zero ischemia laparoscopic partial nephrectomy. Eur J Surg Oncol 40(12): 1731-1737.

\section{Your next submission with Juniper Publishers} will reach you the below assets

- Quality Editorial service

- Swift Peer Review

- Reprints availability

- E-prints Service

- Manuscript Podcast for convenient understanding

- Global attainment for your research

- Manuscript accessibility in different formats

( Pdf, E-pub, Full Text, Audio)

- Unceasing customer service

Track the below URL for one-step submission https://juniperpublishers.com/online-submission.php 